A IMPRESSÃO DE IDEAIS E IDEIAS DE UMA ARGENTINA EM UM PERIÓDICO

BRASILEIRO FEMININO EM MEADOS DO OITOCENTOS

Everton Vieira Barbosa

\title{
A IMPRESSÃO DE IDEAIS E IDEIAS DE UMA ARGENTINA EM UM PERIÓDICO BRASILEIRO FEMININO EM MEADOS DO OITOCENTOS ${ }^{1}$
}

\author{
THE PRINT OF IDEALS AND IDEAS OF AN ARGENTINE IN A FEMALE \\ BRAZILIAN JOURNAL IN MID-NINETEENTH CENTURY
}

Everton Vieira Barbosa²

\begin{abstract}
RESUMO: Observando o contexto argentino durante o governo ditatorial de Juan Manuel de Rosas (1793-1877), buscaremos primeiramente compreender as motivações que levaram alguns opositores políticos a fugirem para outros países. Dentre estes fugitivos, daremos destaque à figura de Joanna Paula Manso de Noronha (1819-1875) e seu exílio no Brasil. Ao escrever o romance histórico argentino Mistérios do Prata (1846) e fundar O Jornal das Senhoras (1852-1855), Manso não só divulgou as suas leitoras o contexto argentino, mas também publicou seu ponto de vista sobre o papel da mulher na sociedade carioca, permitindo, em um segundo momento, identificarmos a circularidade e a importância de seus ideais e ideias através da imprensa em meados do Oitocentos.
\end{abstract}

PALAVRAS-CHAVE: Ditadura argentina; Imprensa; Circulação de ideias e pessoas.

ABSTRACT: Watching the argentine context during dictatorial government of Juan Manuel de Rosas (1793-1877), seek first to understand the motivations that led some political opponents to flee to other countries. Among these fugitives, we will give featured the figure of Joanna Paula Manso de Noronha (1819-1875) and his exile in Brazil. When writing the argentine historical novel Mistérios do Prata (1846) and founded O Jornal das Senhoras (1852-1855), Manso not only disclosed its readers the argentine context, but also published his view on the role of women in carioca society, allowing, in a second moment, identify the circularity and the importance of her ideals and ideas through the press in the mid-nineteenth century.

KEYWORDS: Argentine dictatorship; Press; Circulation of ideas and people.

INTRODUÇÃO

Da Argentina para o Uruguai, do Uruguai para o Brasil. Esta foi a trajetória de viagem de Joanna Paula Manso de Noronha (1819-1875), motivada pela fuga do governo ditatorial argentino, comandado por Juan Manuel de Rosas (1793-1877). Porém, além de Manso de Noronha, muitos opositores de Rosas, chamados de

\footnotetext{
${ }^{1}$ Optou-se por atualizar e traduzir a grafia de todas as fontes citadas neste trabalho.

2 Mestre em História. Doutorando pelo Programa de Pós-Graduação em História da Universidade Federal Fluminense - UFF/Niterói. E-mail: semusico@hotmail.com.
} 
A IMPRESSÃO DE IDEAIS E IDEIAS DE UMA ARGENTINA EM UM PERIÓDICO BRASILEIRO FEMININO EM MEADOS DO OITOCENTOS

Everton Vieira Barbosa

antorrosistas, realizaram o mesmo feito, exilando-se em países como o Brasil, Uruguai e Chile.

Mas além de identificarmos o fluxo migratório destas pessoas, também podemos constatar a circularidade, a produção e a transmissão de ideias de alguns destes agentes históricos em seus novos espaços sociais habitados.

Neste sentido, interessa-nos a circularidade dos ideais e das ideias de Manso de Noronha, devida sua importância na divulgação do contexto argentino e de seu ponto de vista sobre o papel da mulher na sociedade carioca. Autora do romance histórico Mistérios do Prata, em 1846, e fundadora do periódico O Jornal das Senhoras, na cidade do Rio de Janeiro, em 1852, Manso de Noronha é considerada uma das primeiras mulheres a dirigir um jornal em solo brasileiro, servindo de grande inspiração feminina na busca pela equiparação sexual em meados do Oitocentos.

Para identificarmos a circularidade e a importância dos ideais e das ideias de Manso de Noronha por meio da imprensa, buscaremos, inicialmente, observar o contexto argentino durante o governo de Juan Manuel de Rosas, e as motivações que levaram muitos argentinos, inclusive a redatora Joanna, a se exilarem em outros países.

\section{O PRIMEIRO MANDATO DE JUAN MANUEL DE ROSAS E O INÍCIO DO} AUTORITARISMO ARGENTINO

Juan Manuel de Rosas assumiu o governo da província de Buenos Aires em dois momentos. No primeiro, de 1829 a 1832, ele chegou ao poder após a tentativa fracassada do Pacto Cañuelas e do Pacto de Barracas, ambos em 1829, com o general Juan Galo de Lavalle (1797-1841).

O Pacto de Cañuelas foi firmado em 24 de junho de 1829 com o objetivo de terminar a guerra civil na província de Buenos Aires, iniciada desde a revolução de dezembro de 1828, e organizada pelo general unitário e político Juan Lavalle, que se destacou por liderar a revolução de 1828, na qual ordenou o fuzilamento de Manuel Dorrego (1787-1828), governador da província de Buenos Aires em 1820 e entre os anos de 1827 a 1828, pois este não aceitou os acordos com o Brasil e a independência do Uruguai. O Pacto de Cañuelas fracassou, devido a uma fraude do grupo unitário 


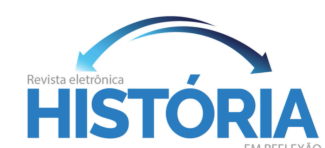

A IMPRESSÃO DE IDEAIS E IDEIAS DE UMA ARGENTINA EM UM PERIÓDICO BRASILEIRO FEMININO EM MEADOS DO OITOCENTOS

Everton Vieira Barbosa

nas eleições para governador, causando, após alguns meses, a retirada de Lavalle para o Uruguai e a posse de Rosas como governador da província. Já o Pacto de Barracas foi firmado em 24 de agosto de 1829 com a finalidade de restabelecer as negociações fracassadas no Pacto de Cañuelas e nomear um novo governador da província de Buenos Aires.

Ao ingressar no poder neste período, Rosas buscou manter e restabelecer a influência perdida dos grandes proprietários de terras, comerciantes portenhos e estrangeiros, durante o governo de Manuel Dorrego (FANLO, 2003, p. 08).

Esta estratégia política possibilitou uma grande aceitação popular, mas também demonstrou os primeiros sinais de autoritarismo, quando "o executivo promoveu uma série de decretos que tendiam a impor as opiniões do governo, silenciando as vozes dissidentes que emanavam de diferentes áreas, inclusive as de seu próprio grupo" (PAGANI; SOUTO; WASSERMAN, 2005, p. 307).

Dentre as leis impulsionadas pelo executivo, temos um decreto imposto em $1^{\circ}$ de fevereiro de 1832, que proibia a venda de livros e ilustrações que atentassem contra a religião e os bons costumes, queimando obras de diversos autores. Porém, um mês antes, alguns periódicos políticos já começavam a ser proibidos por Rosas:

[...] em janeiro de 1832, El Cometa e El Clasificador foram suspensos por terem defendido uma organização constitucional para a República, e a partir daí, a demanda por uma autorização oficial para a publicação de um periódico foi exigida como condição indispensável (PAGANI; SOUTO; WASSERMAN, 2005, p. 307).

A proibição destes jornais serviu como forma de Rosas intimidar seus opositores políticos, dentre eles o pai de Manso, José María Manso, enquanto a proibição e queima de livros, que atentassem contra a Igreja, visava estabelecer uma aliança com a Santa Sé.

Devido aos diversos conflitos entre os partidos unitários e federalistas, e os caudilhos nas diversas províncias argentinas, o exílio foi uma constante no período em países como o Chile, Uruguai, Bolívia e Brasil. "Só para dar um exemplo - talvez algo exagerado -, o exilado tucumano Benjamín Villafañe, antigo secretário de campanha do general Lavalle, nos fala de dez mil argentino emigrados no Chile durante os anos rosistas" (ZUBIZARRETA, 2011, p. 102). 
A IMPRESSÃO DE IDEAIS E IDEIAS DE UMA ARGENTINA EM UM PERIÓDICO BRASILEIRO FEMININO EM MEADOS DO OITOCENTOS

Everton Vieira Barbosa

Desta forma, as medidas autoritárias, somadas as estratégias e alianças políticas com grupos sociais e com seis províncias argentinas, que integravam em 1832 a Comissão Representativa - Buenos Aires, Entre Rios, Santa Fé, Correntes, Córdoba e Medonza -, permitiram caracterizar a imagem de Rosas como a

[...] de "Restaurador das leis", que sem dúvida seria a bandeira de seus primeiros anos de governo, colocando-o como "pacificador" e restaurador da ordem do território, conseguindo assim conseguir a legalidade e legitimidade desejada (HARO; GUTIÉRREZ, 2014, p. 114).

Tais características renderam a Rosas a reeleição em 1832 pela Junta de Representantes, porém proibindo as reformas constitucionais pretendidas pelo governador. Este fato, somado a retirada dos poderes extraordinários (executivo e legislativo), usados durante o primeiro mandato, fez Rosas não aceitar a reeleição.

A Junta de Representantes funcionou entre 1820 e 1854. Formada por um grupo de vizinhos da cidade de Buenos Aires, eles possuíam certo poder aquisitivo e quantidades de terras e tinham a função de nomear o governador da província de Buenos Aires. Porém, durante o segundo mandato de Rosas (1835-1852), a Junta teve seu poder restrito. E foi anulada com a Constituição de Buenos Aires em 1854.

Como Rosas não aceitou a reeleição, a Junta de Representantes elegeu Juan Ramón Balcare (1773-1836), líder militar e político argentino que já havia assumido o governo da província de Buenos Aires, buscando dar continuidade ao modelo rosista de tolerância política.

Apesar de Balcare iniciar seu governo nos moldes de Juan Manuel de Rosas, com o passar dos meses ele se posicionou contrário aos interesses rosistas, fato que culminou na Revolução dos Restauradores e sua deposição.

A Revolução dos Restauradores foi um movimento produzido pela Sociedade Popular Restauradora, ala mais radical dos federais partidários de Juan Manuel de Rosas, em Buenos Aires, no mês de outubro de 1833, em oposição ao governador da província de Buenos Aires, Juan Ramón Balcare. O braço armado da Sociedade era chamado de La Mazorca, atuando entre 1833 a 1846.

Com a deposição de Balcare, a Junta de Representantes propõe novamente o cargo a Rosas, que não aceitou por ser impedido de receber os poderes extraordinários (executivo, legislativo e judiciário). Desta maneira, a Junta designou 
A IMPRESSÃO DE IDEAIS E IDEIAS DE UMA ARGENTINA EM UM PERIÓDICO BRASILEIRO FEMININO EM MEADOS DO OITOCENTOS

Everton Vieira Barbosa

em 04 de novembro de 1833, o general Juan José Viamonte (1774-1843) como novo governador da província de Buenos Aires.

Acusado de pertencer ao partido dos lomos negros, Viamonte renuncia em 1834, passando o cargo a Manuel Vicente Maza (1779-1839) que assume o governo, a contra gosto, por menos de um ano.

Os federais doutrinários, liberais, lomos negros ou os cismáticos constituíram uma facção poderosa dentro do federalismo, principalmente do portenho. Sua ideologia mais liberal, mais institucionalista, pregava o ordenamento do país por meio de uma constituição escrita. Além disso, seus integrantes não simpatizavam nem com o excesso de personalismo de que adoecia seu partido sempre dependente da vontade de Rosas-, nem com o modo através do qual ele costumava autogovernar autoritariamente pela via de poderes extraordinários (ZUBIZARRETA, 2011, p. 111).

Diante dos conflitos e assassinatos entre políticos, Maza deixa o cargo em 1835, obrigando a Junta de Representantes recorrerem novamente a Rosas para ascender ao cargo de governador da província pela segunda vez.

Rosas só aceitaria assumir o cargo se lhe fosse outorgado a suma do poder público, conferindo a ele os três poderes (executivo, legislativo e judiciário).

Diante desta condição, a Junta dos Representantes acata sua solicitação, através de um plebiscito entre os provincianos bonaerenses para referendar o novo governo. "A decisão do Legislativo provincial foi referendada então por 9.720 votos contra 8, sobre uma população aproximada de 55.000 habitantes" (FANLO, 2003, p. 1), iniciando seu segundo mandato, em 1835.

\section{O SEGUNDO MANDATO DE ROSAS E A LEGITIMAÇÃO DO GOVERNO DITATORIAL}

Se no primeiro mandato de Rosas constatamos o uso de um poder autoritário, que causou a restrição à liberdade de imprensa e a fuga de opositores políticos para outros países, no segundo, de 1835 a 1852, observaremos a ampliação deste autoritarismo. 


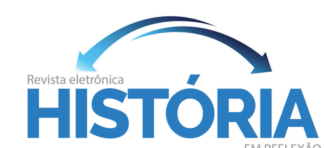

A IMPRESSÃO DE IDEAIS E IDEIAS DE UMA ARGENTINA EM UM PERIÓDICO BRASILEIRO FEMININO EM MEADOS DO OITOCENTOS

Everton Vieira Barbosa

Ao iniciar seu mandato, Rosas já contava com o apoio de muitos estancieiros, o que legitimava seu poder na área rural, porém ele tomou algumas medidas para reforçar seu apoio no espaço urbano.

Por essa razão, assim que ele voltou ao poder, ele procurou fortalecer o regime na cidade e começou a fazê-lo através da eliminação da dissidência e da competição política. Uma série de medidas marcou o curso de suas intenções: ele removeu todo o peso para o, então, importante Legislativo provincial, prendeu seus inimigos do número federal cismático anterior que não havia abandonado a cidade, rejeitou assuntos não confiáveis para ele no exército regular e a administração pública, mandou executar alguns supostos conspiradores e também fuzilou oitenta indígenas nativos em um só dia. Um fato desse teor não era comum na cidade e marcava que havia uma nova dureza governamental (DI MEGLIO, 2008, p. 70-71).

Tais medidas foram possíveis graças à suma do poder público, concedida pela Junta dos Representantes, assim como a atuação de La Mazorca, braço armado da Sociedade Popular Restauradora, criada em 1833 pelos partidários federais de Rosas.

Chamados de apostólicos e com o objetivo de restabelecer os poderes e as propostas rosistas, o grupo federalista atuou nas cidades da província portenha vigiando e perseguindo suspeitos e opositores políticos.

Diante da opressão e violência constatada nas cidades, houve um aumento considerável de membros em La Mazorca, porém as novas adesões não estavam ligadas apenas ao apoio a Rosas, mas podia servir também como uma estratégia de sobrevivência, evitando o exílio.

Mas enquanto alguns membros da elite optaram em aderir a La Mazorca, outros buenairenses resolveram fundar sociedades de estudos, a fim de estabelecer um espaço de discussão, reflexão e produção de conhecimento sobre o contexto argentino, como o caso da Geração de 1837.

Geralmente, uma geração acontece quando seus membros experimentam uma conjuntura e representam isso como um problema compartilhado de índole política e/ou intelectual. Neste caso, os antecedentes que animava as representações e as práticas da Geração de 1837 - e que, cremos a constituiu como tal - era a criação de uma nação, entendendo isso como o nome do projeto com o qual buscavam desenvolver laços sociais e políticos modernos no território rioplatense. (WASSERMAN, 1997, p. 13) 
A IMPRESSÃO DE IDEAIS E IDEIAS DE UMA ARGENTINA EM UM PERIÓDICO BRASILEIRO FEMININO EM MEADOS DO OITOCENTOS

Everton Vieira Barbosa

Deste modo, a Geração de 1837 teve grande importância na Argentina em sua organização e transmissão de uma identidade e ideia de nação, recorrendo à literatura para alcançarem seus objetivos. Este grupo, avesso aos ideais rosistas, buscou difundir suas ideias através de publicações, como no periódico La Moda (1837-1838), caracterizada pelo conteúdo que podia ser satírico, literário ou de distração planejada diante do governo de Rosas.

Diante das três possibilidades de interpretação da revista, Rafael Mantovani demonstra ser uma estratégia política adotada pelos redatores do jornal, "Tanto que o periódico foi censurado pelo próprio Rosas" (MANTOVANI, 2012, p. 52), assim como o Salão Literário foi fechado, ambos no ano de 1838, motivando o exílio de alguns de seus membros, por causa das perseguições feitas pela La Mazorca.

Dentre os membros da Geração de 1837 temos: Juan Bautista Alberdi (18101884), Esteban Echeverría (1805-1851), Félix Frías (1816-1881), Juan María Gutiérrez (1809-1878), Florêncio Valera (1807-1848), Bartolomé Mitre (1821-1906), José Rivera Indarte (1814-1845), Miguel Cané (1812-1863), Luis Domínguez (18191898), Antonio Somellera (1812-1889), Juan Bautista Peña (1708-1869), Juan Cruz Varela (1794-1839) e Mariquita Sánchez de Thompson (1786-1868) que se exilaram no Uruguai; Vicente Fidel López (1815-1903), Domingo Faustino Sarmiento (18111888), Carlos Tejedor (1817-1903) e Antonio Aberastain (1810-1861) que se exilaram no Chile; Marco Avellaneda (1813-1841) que foi morto durante a fuga para a região norte argentina; Benjamín Villafañe (1814-1893) que se exilou na Bolívia; José Mármol (1817-1871) que se exilou no Chile, Brasil, Colômbia e Uruguai.

As restrições e censuras impostas pelo governo de Rosas deixou claro aos seus opositores, dentre eles Manso de Noronha e sua família, a necessidade de organização militar, política e intelectual seja na Argentina ou no exílio.

Portanto, com o uso de poderes ilimitados, por meio da suma do poder público, com o apoio da Mazorca perseguindo e exterminando adversários políticos, com uso de propagandas para doutrinar a população em favor do governo rosista, e com a censura da imprensa, estava instaurado na província bonaerense o regime ditatorial de Rosas, que se estenderia até o ano de 1852. 
A IMPRESSÃO DE IDEAIS E IDEIAS DE UMA ARGENTINA EM UM PERIÓDICO BRASILEIRO FEMININO EM MEADOS DO OITOCENTOS

Everton Vieira Barbosa

E se o poder coercitivo e coativo do governo foram os fatores que motivaram o exílio de muitos argentinos, veremos a seguir, que eles servirão de justificativa para mobilizar os antirrosistas a se unirem para denunciarem por meio da imprensa a ilegalidade do poder, e para se organizarem pela via política e militar com o intuito de acabar com a ditadura de Rosas.

\title{
A ESPERANÇA ESTÁ NO EXÍLIO?
}

No exílio, os antirrosistas se organizaram de diversas formas na tentativa de tirar Juan Manuel de Rosas do poder, sejam em organizações políticas, campanhas militares, ou por meio da imprensa, denunciando os crimes cometidos pelo general.

Dentre as organizações políticas feitas durante o exílio, constatamos a criação de grupos secretos, a fim de se mobilizarem com outros governos e grupos políticos através de dois projetos:

\begin{abstract}
O primeiro, revela uma vinculação com os federais cismáticos, através daqueles que tentariam se aproximar dos governos provinciais de Santa Fé e Entre Rios em momentos em que a tendência hegemônica de Rosas começava a promover certo receio entre os mais influentes caudilhos do interior. Em busca de um entendimento, se encontravam dispostos a deixar de lado suas ideias centralistas e aceitavam o sistema federal enquanto mantivessem diretrizes constitucionalistas. Um segundo projeto, algo posterior e consequente com os dissabores do primeiro, começou a elucubrar dentro da exclusiva esfera unitária. Germinado no final de 1835, baseou-se na elaboração de uma aliança triangular com o ditador de La Paz Andrés de Santa Cruz - Supremo Protetor da Confederação Peruano - boliviana- e com o general Carlos de Alvear, instalado em Buenos Aires (ZUBIZARRETA, 2009, p. 45).
\end{abstract}

Apesar de não obterem êxito em seus projetos, Ignacio Zubizarreta destaca que as sociedades secretas, em sua dinâmica interna, conseguiram manter um núcleo de sociabilidade, permitindo projetarem e formularem estratégias conjuntas, possibilitando uma tomada do poder. Esta dinâmica, além de gerar uma noção de identidade entre eles, objetivava manter a hierarquia entre os setores unitários.

Deste modo, a dinâmica destes grupos, possibilitou uma rede de comunicação entre os exilados, facilitando a articulação de campanhas militares, assim como a atuação antirrosista por meio da imprensa. 
A IMPRESSÃO DE IDEAIS E IDEIAS DE UMA ARGENTINA EM UM PERIÓDICO BRASILEIRO FEMININO EM MEADOS DO OITOCENTOS

Everton Vieira Barbosa

Sobre as campanhas militares, é sabido que elas foram organizadas com diversos objetivos, mas todas possuíam a mesma finalidade: tirar Rosas do poder. Já o uso da imprensa, pode ser identificado nos diversos escritos destes exilados: "as Bases de Alberti; Facundo, Viagens e Recordações da província de Sarmiento; Amalia de Mármol, a edição definitiva do Dogma Socialista de Echeverría" (WASSERMAN, 1997, p. 16).

Estes textos relatavam o contexto argentino durante o governo de Rosas, transmitiam os ideais de uma identidade e nação argentina aos demais exilados e para a população dos países em que estes escritos eram impressos, mantendo viva a esperança do retorno ao lar.

Além deles, temos os escritos de María Sánchez (1786-1868), idealizadora da Geração de 1837:

Este é o caso do diário de 1839-1840, dirigido a Esteban Echeverría, no qual relata os acontecimentos de que foi testemunha em Montevidéu: a expedição de Juan Lavalle, general unitário, a aliança deste com os franceses e a conflitante relação com o presidente uruguaio (e antirrosista) Fructuoso Rivera. Seu epistolário, entretanto, da conta também das alternativas de seu exílio, fornece informações sobre suas atividades sociais e pessoais, faz eco de rumores políticos e militares, e oscila entre o público e o privado, segundo quem seja seu destinatário. Além das personalidades já mencionadas, María Sánchez manteve correspondência com seus filhos (carnais e políticos), especialmente com Florencia Thompson (SÁNCHEZ, 2014, p. 22).

Os escritos de Mariquita Sánchez, colaboradora da Geração de 1837, e administradora da Sociedade de Beneficência até o ano de 1834, são indícios que denotam o contexto social vivenciado por muitos argentinos exilados em outros países, além de caracterizar a esperança pelo fim da ditadura e o reencontro com a família e amigos.

Fundado em 1823, a Sociedade de Beneficência congregou "mulheres portenhas da classe alta num grupo de caráter filantrópico e educativo" (FEITOZA, 2009, p. 45-46). Um dos objetivos principais desta associação era o de prover serviços sociais aos mais desamparados: as mulheres e as crianças. Foi fechado no ano de 1838, por Juan Manuel de Rosas, voltando a funcionar somente em 1852, com a queda do governo rosista. 


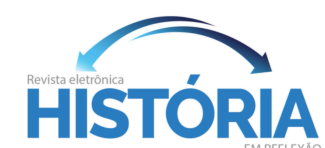

A IMPRESSÃO DE IDEAIS E IDEIAS DE UMA ARGENTINA EM UM PERIÓDICO BRASILEIRO FEMININO EM MEADOS DO OITOCENTOS

Everton Vieira Barbosa

E assim como Sánchez, sua amiga Joanna Paula Manso de Noronha (18191875) foi outra mulher a se exilar e utilizar a imprensa para divulgar e denunciar as atrocidades cometidas pelo governador de Buenos Aires, Juan Manuel de Rosas.

Se as esperanças de voltar ao país de origem foram motivadas por meio dos impressos, perceberemos com Manso de Noronha, que o exílio, além de influenciar a circularidade de pessoas e ideias, permitiu a interação com outras culturas, assim como novas estratégias de sociabilidade e sobrevivência no lar temporário.

\section{JOANNA PAULA MANSO DE NORONHA E SUA TRAJETÓRIA COMO EXILADA}

O exílio de Joanna Paula Manso de Noronha começou no Uruguai, por causa das perseguições de Rosas a seu pai, José María Manso, que participou das atividades revolucionárias de maio de 1810, e por ter sido amigo e colaborador do governo unitário de Bernardino Rivadávia.

Em 1840 tornou-se insustentável e perigosa sua permanência em
Buenos Aires devido à sua evidente oposição ao governo de Juan
Manuel de Rosas e por sua aberta adesão à Geração de 37 . Devido a
esta situação se mudou, junto com sua família, a Montevidéu
(Uruguai). Ali ela fez sua primeira tentativa em matéria de educação
feminina, abriu as portas às jovens da sociedade uruguaia no "Ateneu
de Senhoras", que funcionou em sua casa, Rua São Pedro 246; desta
maneira colaborava com a deplorável situação econômica de sua
família, devido ao fato da emigração e da confiscação dos bens que
possuíam em Buenos Aires (PAGLIARULO, 2011, p. 25).

O Ateneu das Senhoras era "destinado a jovens e senhoras que aprendiam aritmética, leitura, trabalhos, lições de moral, gramática, francês, piano, canto e desenho" (ROITENBURD, 2009, p. 45). Porém, o espaço criado por Manso de Noronha não perdurou por muito tempo. Deste modo, sua curta estadia no Uruguai demonstrou os rearranjos necessários para se adequar à nova realidade de vida e sobreviver neste espaço, ao aplicar seus conhecimentos, em 1841, e disseminar os ideais e ideias trazidos da Argentina.

Destacamos que foi curta sua estadia em Montevidéu, pois em 1842, Manso e sua família migram para o Brasil, devido ao cerco na região uruguaia, feito por Manuel Oribe (1792-1857), aliado de Rosas. 
A IMPRESSÃO DE IDEAIS E IDEIAS DE UMA ARGENTINA EM UM PERIÓDICO BRASILEIRO FEMININO EM MEADOS DO OITOCENTOS

Everton Vieira Barbosa

Porém, os problemas econômicos enfrentados no Brasil fazem Manso de Noronha regressar ao Uruguai, em 1843, assumindo temporariamente a direção de uma escola para meninas e escrevendo poesias no periódico El Nacional, demonstrando que o exílio e suas estratégias de sobrevivência não foram fáceis, além de indicar a perseverança na disseminação de suas ideias e ideais pelo país através da educação e da imprensa.

Deve-se levar em conta que no início do século XIX poucas mulheres tinham acesso à leitura, bem como de direitos civis equiparados aos homens. Conforme afirmam Emília Viotti da Costa (2010) e June H. Hahner (2012), as mulheres eram vistas e caracterizadas por viajantes como agentes passivos, reclusos ao espaço privado, cujas funções se resumiam ao cuidado da casa, do marido e dos filhos.

Uma vez que elas possuíam grande parte do tempo no espaço doméstico, a dedicação destas mulheres à leitura e à escrita lhes aproximavam da imprensa, que a partir da década de 1820 começava a dar atenção à este público com assuntos voltados à moda, receitas caseiras, poesias e folhetins.

Até metade do século XIX, já era considerável o número de periódicos femininos publicados no Brasil e fortalecendo o acesso das mulheres à imprensa, tanto como escritora quanto redatora, assim como Joanna Paula Manso de Noronha.

Nesta perspectiva, a atuação feminina na imprensa pode ser compreendida em uma das muitas relações que perpassam a história das mulheres. Rachel Soihet (1997), Carla Bassanezi Pinsky (2013) e Joan Scott (1992) compreendem a história das mulheres em uma perspectiva plural, dando visibilidade às suas complexidades e individualidades, perpassadas por lutas simbólicas de poder e pelas relações de gênero como construções sociais.

Diante destas lutas simbólicas e das relações de gênero construídas socialmente, Constância Lima Duarte (2008) dá visibilidade às dificuldades enfrentadas por muitas mulheres no decorrer do século XIX para alcançarem a equiparação de direitos entre homens e mulheres, e os meios encontrados, via imprensa e educação feminina, na conquista de certas reivindicações políticas e civis.

Tais dificuldades são constatadas novamente com Manso de Noronha, devida a necessidade em sair do Uruguai e retornar ao Rio de Janeiro, no ano de 1844, por 


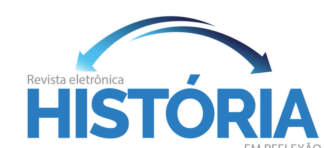

A IMPRESSÃO DE IDEAIS E IDEIAS DE UMA ARGENTINA EM UM PERIÓDICO BRASILEIRO FEMININO EM MEADOS DO OITOCENTOS

Everton Vieira Barbosa

problemas econômicos, quando ela conhece seu futuro esposo, o músico português Francisco de Sá Noronha.

Para se adequar a nova realidade de esposa, Manso de Noronha viajou com seu marido pelos Estados Unidos e Cuba com o intuito de divulgar a carreira do músico, assim como observar os métodos de ensino nestes países.

Se estas viagens não alcançaram as expectativas de Manso de Noronha e de seu marido, foram nelas que nasceram suas duas filhas, Eulália e Hermínia, assim como a criação de seu romance histórico Mistérios do Prata, que só chegou ao público brasileiro em 1852, ano de criação de O Jornal das Senhoras (1852-1855).

Sendo uma das primeiras redatoras e diretoras de um periódico feminino, onde "O grande elemento definidor ainda é o sexo de suas consumidoras" (BUITONI, 1986, p. 08), Manso de Noronha objetivava o melhoramento social e a emancipação moral da mulher na sociedade, além de imprimir assuntos sobre críticas ao racismo, sobre a escravidão, poemas e informações culturais e musicais como partituras, com o intuito de divulgar a atividade musical de seu marido.

No caso dos textos publicados pelas redatoras do O Jornal das Senhoras em prol dos direitos femininos:

\begin{abstract}
A busca pela equiparação intelectual e moral e o melhoramento social feminino, portanto, eram os principais objetivos destas mulheres que, conhecendo sua condição de submissão em uma sociedade patriarcal, visavam, por meio deste impresso periódico, dar visibilidade a estas questões, bem como superar esta estrutura social rígida, via acesso igualitário à educação e inserção no mundo do trabalho (BARBOSA, 2018, p. 96).
\end{abstract}

Com o impacto das ideias sobre o melhoramento social e a emancipação moral feminina publicadas por Manso de Noronha em O Jornal das Senhoras surgiram apoiadores, mas também opositores como alguns homens que escreveram logo no segundo mês de impressão do jornal uma carta, intitulada O Homem, questionando a iniciativa da redatora argentina.

Porém, sem temer os opositores do jornal, Manso de Noronha seguiu com suas publicações com textos em prol da mulher e com seu romance histórico Mistérios del Plata, relatando as atrocidades do governo de Rosas em um texto adaptado para a leitura estrangeira, neste caso a brasileira: 


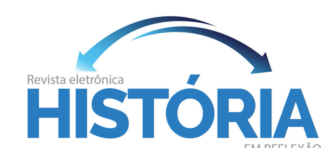

A IMPRESSÃO DE IDEAIS E IDEIAS DE UMA ARGENTINA EM UM PERIÓDICO BRASILEIRO FEMININO EM MEADOS DO OITOCENTOS

Everton Vieira Barbosa

O prólogo cumpre a função de informar ao leitor estrangeiro, inconsciente da realidade social, política e linguística da Argentina, de como deve ler e interpretar o texto de ficção, pois Manso sabia muito bem que a eficiência do aparato político propagandístico de Rosas havia conseguido que alguns países europeus, especialmente a Inglaterra, consideraram o governo de Rosas um regime de direito natural e seu objetivo era que os leitores estrangeiros entendessem a falsidade de tal suposição (GRAU-LLEVERÍA, 2010, p. 4).

Tais estratégias editoriais permitiam aos leitores de seu periódico um maior contato com a realidade argentina, assim como adesão e colaboração às ideias nele transmitidas.

Além do prólogo, GRAU-LLEVERÍA (2010) destaca que também havia as notas de rodapé, divididas explicações linguísticas, diante de termos específicos da Argentina, e notas de caráter histórico, homenageando as vítimas do governo rosista e denunciando quem o ajudava.

Esta estratégia paratextual, além de facilitar a leitura aos leigos sobre o contexto argentino, contribuiu na adesão à campanha brasileira contra do governo de Rosas, iniciada desde 1851.

Tal mobilização, através de um acordo entre Brasil, Uruguai, e as províncias argentinas de Entre Rios e Correntes, resultou na Batalha de Monte Caseros, em fevereiro 1852 e o fim do governo de Rosas.

Com isso, terminara o exílio antirrosista de Joanna Paula Manso de Noronha, Mariquita Sánchez, alguns membros da Geração de 1837 e demais fugitivos do governo rosista. No caso de Manso de Noronha, sua volta à Argentina também foi motivada pelo fim de seu casamento com o músico Noronha, a proibição de seu ingresso na faculdade de medicina no Brasil e a volta de sua família a Buenos Aires (LOBO, 2009, p. 48).

Desta forma, Manso de Noronha não continuou com a publicação de seu romance histórico em $O$ Jornal das Senhoras, e ela passou a direção do periódico para a redatora Violante Atabalipa Ximenes de Bivar e Vellasco (1817-1875), retornando à Argentina e buscando retomar sua vida antes do exílio.

Joanna Paula Manso de Noronha ainda voltou a residir no Brasil entre os anos de 1854 e 1859, atuando em alguns teatros no Rio de Janeiro, porém ao regressar novamente e definitivamente à Argentina, ela pode reconstruir sua vida e garantir o futuro de suas filhas. 


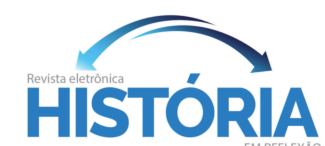

A IMPRESSÃO DE IDEAIS E IDEIAS DE UMA ARGENTINA EM UM PERIÓDICO BRASILEIRO FEMININO EM MEADOS DO OITOCENTOS

Everton Vieira Barbosa

CONSIDERAÇÕES SOBRE A IMPORTÂNCIA DA CIRCULARIDADE DE MANSO E DE SUAS IDEIAS E IDEAIS

Apesar de Manso de Noronha não ter dado continuidade em seu romance histórico Mistérios do Prata no periódico O Jornal das Senhoras, sua publicação, ligada à ideia de identidade nacional argentina, deu visibilidade ao contexto do governo de Rosas, às atrocidades feitas pela La Mazorca, assim como os motivos de se opor e acabar com este regime político.

Já O Jornal das Senhoras (1852-1855), continuado posteriormente por Violante Atabalipa Ximenes de Bivar e Vellasco (1817-1875), durante onze meses, e por Gervasia Nunezia Pires dos Santos Neves (1824-1872) durante dois anos e sete meses, manteve os objetivos de Manso de Noronha ao buscar o melhoramento social e a emancipação moral da mulher através da imprensa. Além disso, ele continuou impresso com informações sobre moda, música, os espaços de sociabilidade carioca, a necessidade do ensino feminino, legitimando a participação feminina na direção do periódico.

Portanto, apesar de a experiência no exílio modificar significativamente a vida de muitos argentinos, assim como a de Manso de Noronha, tornando-a neste período professora, esposa/desquitada, mãe, dramaturga e redatora, suas estratégias de sobrevivência através do uso da imprensa, para dar voz e visibilidade às mulheres e aos argentinos exilados, colaboraram para que ela e outros fugitivos alcançassem seus maiores objetivos: dar visibilidade às reivindicações femininas e voltar para casa.

\section{REFERÊNCIAS}

BARBOSA, Everton Vieira. Páginas de sociabilidade feminina: sensibilidade musical no Rio de Janeiro Oitocentista. São Paulo: Editora Alameda, 2018.

BUITONI, Dulcília Helena Schroeder. Imprensa feminina. São Paulo: Editora Ática, 1986. 


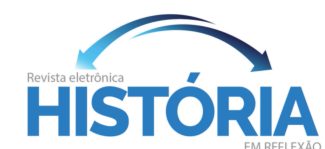

A IMPRESSÃO DE IDEAIS E IDEIAS DE UMA ARGENTINA EM UM PERIÓDICO BRASILEIRO FEMININO EM MEADOS DO OITOCENTOS

Everton Vieira Barbosa

COSTA, Emília Viotti da. Da Monarquia à República: momentos decisivos. $9^{\circ}$ ed. São Paulo: Editora Unesp, 2010.

DI MEGLIO, Gabriel. La Mazorca y el orden rosista. Prohistoria, Año XII, número 12, Rosario, Argentina, primavera, 2008, pp. 69-90.

DUARTE, Constância Lima. Nísia Floresta e a educação feminina. In: LÔBO, Yolanda; FARIA, Lia (Orgs.). Vozes femininas: do império e da República. Rio de Janeiro: Quartet: FAPERJ, 2008, p. 105-144.

FANLO, Luis. Caudillo entre caudillos: Juan Manuel de Rosas y las guerras civiles argentinas. Revista Contratiempos, Año 1, n² 2, primavera, 2003, pp. 1-20.

FEITOZA, Tatiana Mariano. Los Misterios del Plata: literatura feminina e rosismo na Argentina no século XIX. Dissertação (Mestrado), UFRJ, Faculdade de Letras, Rio de janeiro, 2009.

GRAU-LLEVERÍA, Elena. La ficción política romántica en Los misterios del Plata. Episodios de la época de Rosas, escritos en 1846 de Juana Paula Manso. Decimonónica. Vol. 7 nº 1, Winter/Invierno, 2010, pp. 1-20.

HAHNER, June H. Honra e distinção das famílias. In: PINSKY, Carla Bassanezi; PEDRO, Joana Maria. Nova história das mulheres. São Paulo: Contexto, 2012, p. 43-64.

HARO, Agustín; GUTIÉRREZ, María Florencia. La política de Juan Manuel de Rosas durante su primer mandato. Revista Semina, Passo Fundo-RS, v. 12, n. 1, 2014, p. 110-128.

LOBO, Luiza. Juana Manso: uma exilada em três pátrias. Niterói, v. 9, n. 2, $1^{\circ}$ sem. 2009, p. 47-74. 
A IMPRESSÃO DE IDEAIS E IDEIAS DE UMA ARGENTINA EM UM PERIÓDICO BRASILEIRO FEMININO EM MEADOS DO OITOCENTOS

Everton Vieira Barbosa

O Jornal das Senhoras. Rio de Janeiro: Tipografia do Jornal das Senhoras, 18521855. Disponível em < http://goo.gl/Q6JYbe >. Acesso em 05 fev. 2018.

Pacto de Barracas. 24 ago. 1829. Argentina. Disponível em < http://www.elortiba.org/doc/pac_barr.pdf >. Acesso em 05 fev. 2018.

Pacto de Cañuelas. 24 jun. 1829. Argentina. Disponível em $<$ http:// hum.unne.edu.ar/academica/departamentos/historia/catedras/hist_argen_indep/pact os_trat_acuer/pacto_de_canuelas.pdf>. Acesso em 05 fev. 2018.

PAGANI, Rosana; SOUTO, Nora; WASSERMAN, Fabio. El ascenso de Rosas al poder y el surgimiento de La Confederación (1827-1835). In: GOLDMAN, Noemí (Org.). Nueva Historia Argentina. Revolución, república, confederación (18061852). Tomo III. $2^{\mathrm{a}}$ ed. Buenos Aires: Sudamericana, 2005, pp. 283-321.

PAGLIARULO, Elisabetta. Juana Paula Manso (1819-1875) presencia femenina indiscutible en la educación y en la cultura argentina del siglo XIX, con proyección americana. Rev. Hist. Educ. latinoam. vol. 13, n 17. Tunja, Jul./Dez., 2011, pp. 1742.

PINSKY, Carla Bassanezi. Gênero. In: Novos temas nas aulas de história. $2^{\mathrm{a}}$ ed. $2^{\mathrm{a}}$ reimp. São Paulo: Contexto, 2013.

ROITENBURD, Silvia N. Sarmiento: entre Juana Manso y las maestras de los EEUU. Recuperando mensajes olvidos. Antíteses, vol. 2, n. 3, jan.-jun., 2009, pp. 39-66.

SÁNCHEZ, Santiago Javier. Mariquita Sánchez: ¿Madre de la Patria o feminista patriótica? Processos Históricos: Revista de Historia y Ciencias Sociales, № 25 , enero-julio, Mérida, Venezuela, 2014. 
A IMPRESSÃO DE IDEAIS E IDEIAS DE UMA ARGENTINA EM UM PERIÓDICO BRASILEIRO FEMININO EM MEADOS DO OITOCENTOS

Everton Vieira Barbosa

SCOTT, Joan. História das mulheres. In: BURKE, Peter (Org.). A escrita da história: novas perspectivas. $7^{\text {a }}$ reimp. Trad. Magda Lopes. São Paulo: Editora Unesp, 1992, p. 63-96.

SOIHET, Rachel. História das mulheres. In: CARDOSO, Ciro Flamarion; VAINFAS, Ronaldo. Domínios da História: Ensaios de teoria e metodologia. $5^{a}$ ed. Rio de Janeiro: Editora Campus, 1997.

WASSERMAN, Fabio. La Generación de 1837 y el proceso de construcción de la identidad nacional argentina. Boletín del Instituto de Historia Argentina y Americana Dr. Emilio Ravignani. Tercera Serie, $\mathrm{n}^{\circ} 15,1^{\mathrm{er}}$ semestre de 1997, pp. 734.

ZUBIZARRETA, Ignacio. Los Unitarios: faccionalismo, prácticas, construcción identitaria y vínculos de una agrupación política decimónica, 1820-1852. (Inauguraldissertation) zur Erlangung des Grades eines Doktors der Philosophie am Fachbereich Geschichts- und Kulturissenchaften der Freien Universität Berlin, 2011.

. Una sociedad secreta en el exilio: los unitarios y la articulación de políticas conspirativas antirrosistas en el Uruguay, 1835-1836. Boletín del Instituto de Historia Argentina y Americana. Dr. Emilio Ravignani, Tercera serie, n 31, Buenos Aires, ene./dic. 2009, p. 43-78.

Artigo recebido em 28/02/2018 Artigo aceito em 18/06/2018 